\title{
Comparison of tibialis anterior and gastrocnemius muscles activation on balance training devices and hoverboard
}

\author{
Khairiyah Abdul Rahman a, Aizreena Azaman a,c , Hadafi Fitri Mohd Latip b,c, Mohd Azuwan Mat \\ Dzahir ${ }^{d}$, and Malarvili Balakrishnan ${ }^{a}$ \\ a Department of Biotechnology and Medical Engineering, Faculty of Biosciences and Medical Engineering, Universiti Teknologi Malaysia, 81310 \\ UTM Johor Bahru, Johor, Malaysia \\ ${ }^{b}$ Department of Clinical Science, Faculty of Biosciences and Medical Engineering, Universiti Teknologi Malaysia, 81310 UTM Johor Bahru, Johor, \\ Malaysia \\ c Sport Innovation Technology Center ,Universiti Teknologi Malaysia, 81310 UTM Johor, Malaysia \\ a Deparment of Applied Mechanics and Design, Faculty of Mechanical Engineering, Universiti Teknologi Malaysia, 81310 UTM Johor Bahru, Johor, \\ Malaysia \\ *Corresponding author: aizreena@biomedical.utm.my
}

Article history

Received 15 October 2017

Accepted 6 December 2017

\begin{abstract}
Balance training devices such as wobble board, basu ball and balance cushion are the tool used in balance training exercise programme in order to improve muscle strength and restore posture balance due degeneration of body function or injury. Recently, self-balancing scooter such as Segway and hover board showed a positive effects on rehabilitation. However, it is less known how these devices affect muscle physiological properties. This study aims to measure ankle muscles activation on difference balance training devices and hover board. In addition, a comparison between these device will be done in order to identify if hover board has a promising feature to be an alternative balance training device. In this research, surface EMG (sEMG) was used to record tibialis anterior and gastrocnemius muscle activities. Seventeen healthy subjects were required to stand on three different types of balance training device such as wobble board, balance cushion, bosu ball and a hover board. They were asked to maintain their standing position on each devices for two minutes. Both time domain and frequency domain analysis were used to identify the features of the EMG signal. Time domain analysis measurement involved average rectified value (ARV) and root mean square (RMS), meanwhile for frequency domain, median frequency (MDF) of the signal were measured. The results shows that, the RMS is differed significantly between the balance training devices $(p<0.05)$ for tibialis anterior muscle but not gastrocnemius muscle. Meanwhile, no significant difference between the devices in the ARV and the MDF value ( $p>0.05)$. Besides, it was observed that less stable devices have increased muscle activity were observed. There is not much difference between hover board and the other devices in term of physiological effects of both tibialis anterior and gastrochemious muscle. It is also suggested that hover board offers a promising feature to be an alternative device for balance training device.
\end{abstract}

Keywords: Muscle activity, electromyography, balance training device

\section{INTRODUCTION}

Balance abiliy is an intrinsic ability of a person to maintain, attain and return of balance. This ability is depends on individual's sensory and motor system. A proper spatial and posture orientation also effect individual's balance ability (Azaman \& Yamamoto, 2014). Balance ability affected by deterioration of vision, vestibular and somatosensory inputs that may caused by ageing, injuries and diseases such as stroke an ankle injury. Besides, it also affected by weakened muscle strength. There are few devices that commonly use for balance training and therapy such as wobble board, passive robotic wobble board, basu ball and balance cushion (Latip, Omar, Shahrom, Azmi, \& Ridhwan, 2015; Wolburg, Rapp, Rieger, \& Horstmann, 2016). These devices are normally presrcibe by a physician based on type and severity of injuries or disease.

In general, these device function to create inbalance condition to patient. The patient will initiate balance control movement to maintain any particular position and thus, triggers muscles activation and modulate range of motion (ROM) at a particular joint. According to previous research, ankle joint and muscles such as gastrochemious and tibilis anterior play an important role as a terminal struture of the lower limb that contribute to movement as well as stability. Furthermore, it was reported that each of these muscle will trigger at a particular movement. The gastrocnemious muscles will be activated to keep balance if there is sway in posterior direction of the body the meanwhile the tibialis anterior muscle will be stimulated when there is a sway towards anterior direction of the body(Lee, Yoon, Kim, Kim, \& Kim, 2012; Yoon, 2017).

However, it is less known how the available devices differ from each other especially interm of physiological aspects. Wobble board was reported able to improve stability and avoid ankle injuries. In previous research, lower limb muscles activities during standing on different type of wobble board such as Jacobs, Freeman, and Lateral were compared (Cimadoro, Paizis, Alberti, \& Babault, 2013). The 
results showed that only Freeman and Lateral type were recommended to ahtletes meanwhile for adults, Jacobs type should be applied first before they can use other type of wobbler board. These findings were based on root-mean square (RMS) value of muscles activation.

On the other hands, Thomas Wolburg et al (2016) have compared effects of mucsle activation during standing on different stability level of balance cushion (Wolburg et al., 2016). The findings suggested that less stable device reqired more muscle activity and it was recommeded for rehabilitation process. Similar results was reported by Kang and Hyong (2012) when compared to amount of air pressure inflated in rubber air disc (Kang \& Hyong, 2012). Thus, further study is still needed to compare between the available balance training devices.

Training or exercise for balance and muscle strength training often conducted in gym or other indoor setting. These 'indoor' type of training devices somehow may delay the improvement stage as patient easily get bored and demotivated. According to previous study, 17 percent of respondence felt too easy and bored with home programme of balance exercise or HEP (Hinman, 2002).

Recent years, human computer interface (HCI) technology such as virtual reality and gamification methods were embebded into conventional methods to make balance training regimes more intereting (Fogg, 2002; Oinas-Kukkonen \& Harjumaa, 2008). Gamification of exercise or training increased self-motivation and enjoyment of exercise (Goh \& Razikin, 2015). In 2016, the use of HCI technology and gamification approach were reported able to create a fun and engaging way of doing rehabilitation for upper limbs in home environment (Karashanov, Manolova, \& Neshov, 2016). Besides, this approach is effective in the context of education and learning process (Zuckerman \& Gal-Oz, 2014). However, the effective of gamification interm of physical activity is still remain unclear.At this moment, outdoor exercise is still the main approach that can accumulate more physical activity compared to indoor exercise (Kerr et al., 2012). Thus, alternative exercise device for balance training with gamification and outdoor feature is needed.

Other than the HCI technology, latest technology for transportion can be an anternatif tools for rehabilitation. Based on current products and existing technology, self-balancing transportation devices such as Segway and hoverboard have shown a promising features to improve quality of life for individual with disabilities in term of pysiological aspects. In 2010, a study on the use of Segway among individual with mobility disabilities was conducted and it was reported that Segway able to meet their mobility goals (van der Woude et al., 2010). Segway and hoverboard are fictional levitating board used for personal transportation. The boards are generally depicted as resembling a skateboard with lateral wheel. Nowadays, these board have become phenomenon and were used during leisure time or means of transportation. Besides, these boards are suitable for both indoor and outdoor environment. Segway normally comes with handlebars but not for hoverboard.

Hoverboard apply almost a similar approaches like balance training device as mentioned previously where a person is required to maintain their balance position and initiate a movement at their foot in order to move towards their desired direction. As hoverboard resamble the existing balance training device characteristic, it is worth to investigate it effect to human body. Recently, less research has been conducted to investigate therapeutic features of both hover board and Segway. Other wheels type board such as skateboard was reported improved cardiovascular health and fitness (Amtmann, Loch, Todd, \& Spath, 2013). Besides, recent article claimed that skateboarding may have therapeutic effect on children with autism, but no scientific evidence recorded yet (Nieratko, 2010, June 23)

Surface eletromyography (sEMG) signal provided a rich and useful information to investigate characteristic of muscle activation (Phinyomark, Thongpanja, Hu, Phukpattaranont, \& Limsakul, 2012). Several signal features and analysis can be used to investigate the characteristic of muscle such as root mean square (RMS), median frequency (MDF), average rectified value (ARV) and many more. These features can help to identify muscle characteristic such as strength,localised fatigue, contribution and conduction velocity (Phinyomark et al., 2012; Schwartz et al., 2014). The sEMG is universally used in rehabilitation research to identify physiological properties of muscle (Cimadoro et al., 2013; Pfusterschmied et al., 2013; Wolburg et al., 2016).

Thus, this study aims to measure ankle muscles activation on difference balance training devices and hover board. Besides, a comparison between these device will be done in order to identify if hover board has a promising feature to be an alternative balance training device in future.

\section{EXPERIMENTAL}

\section{Subject preparation}

In this study, 17 healthy subjects were involved (age: $23.35 \pm 0.17$ years old; weight: $61.12 \pm 3.57 \mathrm{~kg}$ and height: $159.59 \pm 1.24 \mathrm{~cm}$ ). 7 of them were men and the rest were women. They were recruited from general student population in Faculty of Bioscience and Medical Engineering, Universiti Teknologi Malaysia, Malaysia.

Each subject was fully briefed regarding the experiment protocol and possible risk. They were provided the consent form of participation that followed the Declaration of Helsinki. Subjects were excluded from the experiment if they have any health problem, injury, abnormal BMI, or history of fall.

\section{Experiment protocol}

Before the experimenet started, subjects were asked to undergo balance screening test. In this study, Stork Balance Stand Test were used. The subject needed to stand one leg with their arm across the chest for maximum of 2 minutes. The standing total time were recorded. The rating of the test is shown in Table 1 below. Subjects who scored less than 40 seconds were eliminated from this study.

Table 1 Stork Balance Stand Test Score

\begin{tabular}{cc}
\hline Rating & Score (seconds) \\
\hline Excellent & $>50$ \\
Good & $40-50$ \\
Average & $25-39$ \\
Fair & $10-24$ \\
Poor & $<10$ \\
\hline
\end{tabular}

Each subjects were given training sessions to help them familiarized with the devices as shown in Fig. 1. The experiment were only started when subject already feel confortable with all the devices.

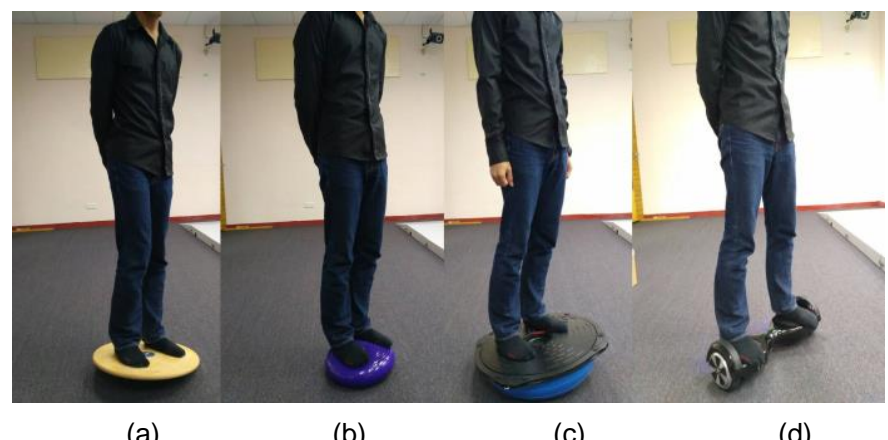

Fig. 1 Balance training device used in the experiment, from left (a) wobble board (WB); (b) balance cushion (BC); (c) bosu ball (BB); and (d) hover board (HV).

After that, subject were asked to stand confortably with natural foot range and tried to maintain their standing position on four different device such as wobble board (WB), balance cushion (BC), bosu ball (BB) and hover board (HV) for 2 minutes in random sequence as shown in Fig. 1. 
They were needed to undergo three trials for each devices. Besides, they were given 2 minutes of rest between the trials. The stability level of these device were achieved based on different structural design and material properties as shown in Table 2 .

Table 2 Propertise of balance training devices.

\begin{tabular}{|c|c|c|c|}
\hline Devices & $\begin{array}{l}\text { Surface } \\
\text { Material }\end{array}$ & Dimension & $\begin{array}{c}\text { Stability } \\
\text { Level }\end{array}$ \\
\hline Balance & Plastic with & Dimension: $6 \mathrm{~cm}$ & Very \\
\hline Cushion & $\begin{array}{c}\text { concentric } \\
\text { groove } \\
\text { surface }\end{array}$ & $\begin{array}{l}W \times 35 c \\
m L \times 36 \mathrm{~cm} \mathrm{H}\end{array}$ & stable \\
\hline Hover & Plastic & Dimensions: 24.5" & Slightly \\
\hline Board & & $\mathrm{L} \times 9 " \mathrm{~W} \times 8.75^{\prime \prime} \mathrm{H}$ & unstable \\
\hline $\begin{array}{l}\text { Wobble } \\
\text { board }\end{array}$ & Wood & $\begin{array}{l}\text { Diameter: } 20 \mathrm{in} . \\
\text { Tilt angle: } 15 \mathrm{deg}\end{array}$ & Unstable \\
\hline Bosu Ball & Plastic & $\begin{array}{l}\text { Diameter: } 25 \text { in. } \\
\text { Height: } 10 \text { in. }\end{array}$ & $\begin{array}{c}\text { Very } \\
\text { unstable }\end{array}$ \\
\hline
\end{tabular}

\section{Data recording}

Muscles activity were recorded using EMG (TMSI, Porti 7, Netherland). Bipolar surface electrodes were placed on tibialis anterior and lateral gastrocnemius muscles of the dominant lower limb as shown in Fig. 2. The recording area was shaved and alcohol swabs was used to remove the top layer of skin to reduce skin impedance. All cables were fixed properly on subject's limb using clinical grade tape to avoid noise and motion artifact.

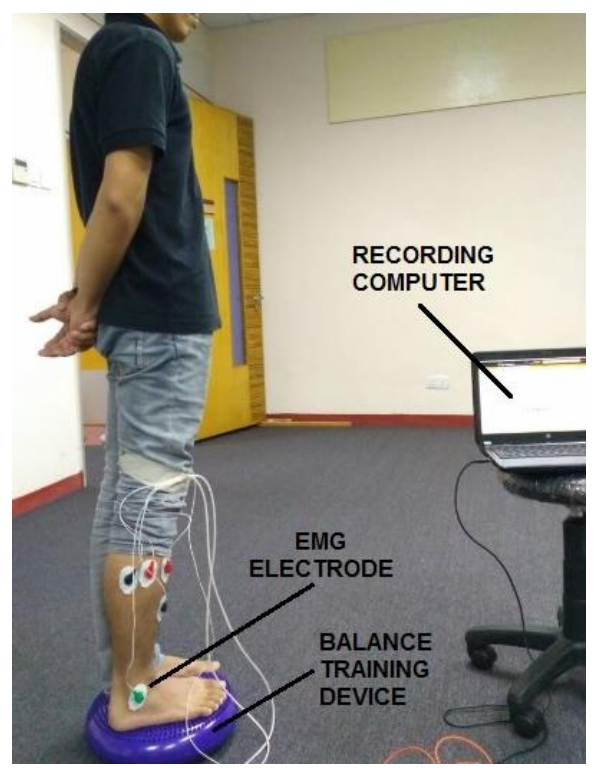

Fig. 2 Experiment set up. EMG electrodes were placed on the dominant leg. Recording computer was used to record and process raw data from TMSI system.

\section{Data analysis}

The EMG signals were processed using MATLAB software. The preprocessing started by detrend process. The signals were detrended to remove unwanted signal that caused signal distortion. Then, the signals were rectified to find the absolute data point. The filtering porcess were done by using Butterworth Band Pass filter between 50 to $400 \mathrm{~Hz}$ to remove noise from motion artifact and unwanted high crosstalk.
In this study both frequency and time domain analyses were done. For time domain analysis, the average rectified value (ARV) and root mean square (RMS) value were measured. The ARV was measured by averaging the filtered signal which commonly used to indicate the amount of muscle contribute for each devices as shown in Eq. 1.

$$
\mathrm{ARV}=\frac{\mathbf{1}}{T} \int_{(t-T)}^{t} f(t) \cdot d t
$$

where, $\mathrm{T}$ is the time for continuous wave function and $\mathrm{f}(\mathrm{t})$ is the filtered signal.

Meanswhile, value of RMS was measured by averaging the square root of the filtered signal using Eq. 3. Value of the RMS will indicate the muscle activation during the trials (Konrad, 2005).

$$
R M S(f(t))=\sqrt{\frac{1}{T} \int_{t-T}^{t} f(t)^{2}}
$$

where, $\mathrm{T}$ is the time for continuous wave function and $\mathrm{f}(\mathrm{t})$ is the filtered signal.

Based on the average rectified value (ARV) calcultion, another modification used to compare innervation ratios between balance training devices is by using Input Percentage Value (Konrad, 2005). The formula to calculate Input Percentage (Input \%) value is shown in Eq 3.

$$
\text { Input } \%=\frac{A R V}{\sum A R V} x 100 \%
$$

For frequency domain analysis, median frequency (MDF) were measured. Fast fourier transform (FFT) was applied to the filtered signal to get the power density spectrum. Half of the total power spectrum then calculated to get the median frequency as shown in Eq 4 (Phinyomark et al., 2012). Fig 3 below shows the median frequency in power spectrum graph.

$$
\sum_{j=1}^{M D F} P j=\sum_{j=M D F}^{M} P j=\frac{1}{2} \sum_{j=1}^{M} P j
$$

where $\mathrm{P}$ is the EMG power spectrum.

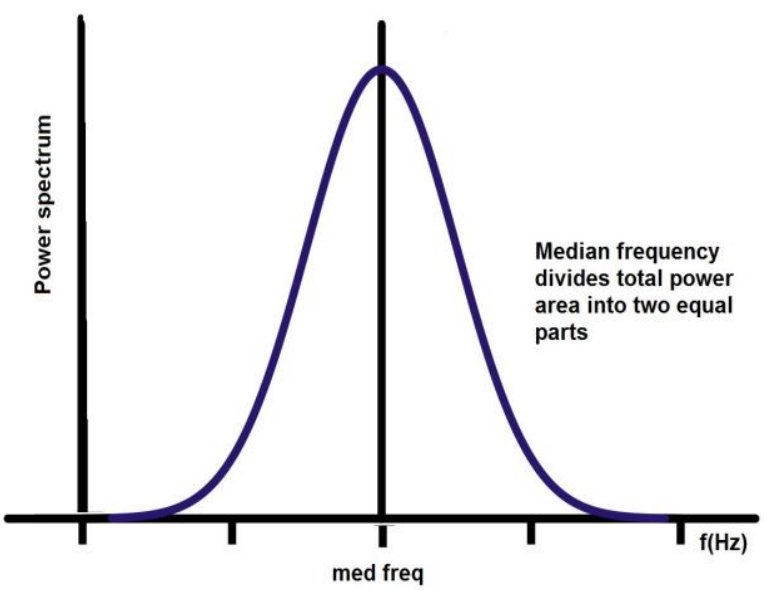

Fig. 3 Power spectrum graph. Eq. 4 can be used to determine the value for median frequency (MDF). Median frequency is the parameter that devices total power area into two equal parts. This parameter has been used to determine muscle fatigue.

The decreasing of the median frequency will indicate the muscle fatigue. According to previous research, conduction velocity $(\mathrm{CV})$ measured velocity of action potential spreads throughout muscle fibers and the decreasing of the muscle conduction velocity causes the median frequency to decrease (Cifrek, Medved, Tonković, \& Ostojić, 2009; Stirn, Jarm, Kapus, \& Strojnik, 2013). 
Basic statistical analysis such as mean, and standard deviation were used. All statistical analysis and test were performed using Excel Software. Data from the three trials were averaged. Besides, one-way analysis of variance (ANOVA) was used to measure significant difference of muscle activity between balance training devices with the significance level $\alpha=0.05$ was selected.

\section{RESULTS}

\section{Muscle activity on different balance training devices}

As mentioned before, the ARV measurement indicated muscle contribution for a particular motion or device. For this study, the results shows that the ARV of the tibialis anterior muscle for the balance training devices are almost the same. There was no significant interaction of ARV between the balance training devices $(\mathrm{p}=0.9798)$. The highest ARV for tibialis anterior was for balance cushion as shown in Fig 4. The ARV value for the bosu ball and hover board is almost same.

For the gastrocnemius muscle, there was no significant different of the ARV between the balance training devices ( $p>0.05$ ). The highest contribution of muscle for gastrocnemius muscle was recorded by bosu ball. The height of the bosu ball which is $55 \mathrm{~cm}$ off floor affect the muscle contribution. More muscle strength needed to keep the stability of people on the bosu ball.

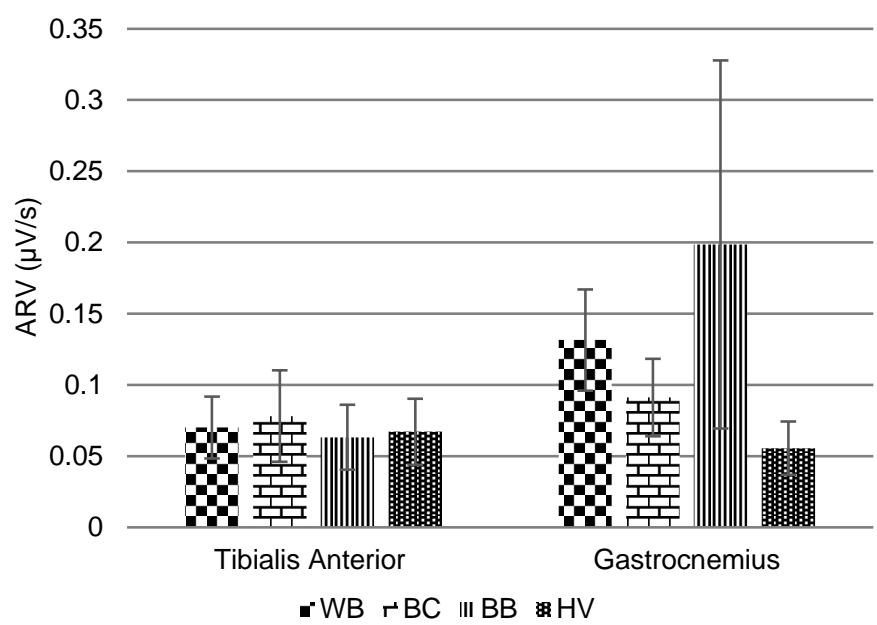

Fig. 4 The average rectified value (ARV) of the tibialis anterior and gastrocnemius muscle for balance training devices.

Fig. 5 below shows the percentage of the contribution of the muscles for each devices. This measurement is used to compare the innervation ratio between the training devices.

For the wobble board and bosu ball, the used of the antagonist muscle (gastrocnemius) is more that agonist (tibialis anterior). These was similar with balance cushion, and bosu ball. But, the pattern is slighly difference for hover board where it used more agonist muscle than antagonist muscle. The highest contribution of tibialis muscle to the balance training devices is hover board which contributed about $52.18 \%$ followed by balance cushion $(46.17 \%)$, wobble board $(34.76 \%)$ and bosu ball (24.16\%).

For gastrocnemius muscle, the highest contribution is bosu ball which is $75.84 \%$, followed by wobble board $(65.23 \%)$, balance cushion $(53.83 \%)$ and hover board $(47.82 \%)$.

Furthermore, Fig. 6 shows the RMS value of the musles. The result shows that there is a significant different between the balance training devices for tibialis anterior muscle $(\mathrm{p}=0.0004)$. However, the RMS for gastrocnemius muscle recorded no significant different between the balance training devices $(\mathrm{p}=0.0932)$.

The wobble board is the highest RMS for both muscle. The RMS measurement graph indicates the level of muscle activation pattern as it was increased from hover board, bosu ball, balance cushion and wobble board for both muscles as shown in Fig. 6. As mentioned in data analysis section, the RMS analysis measures level of the muscle activation at a particular condition.

In this study, it is observed that there is not much differences on the RMS and the ARV between conventional balance training device and hover board. This indicates that hover board produce almost a similr physiological response to the other devices.

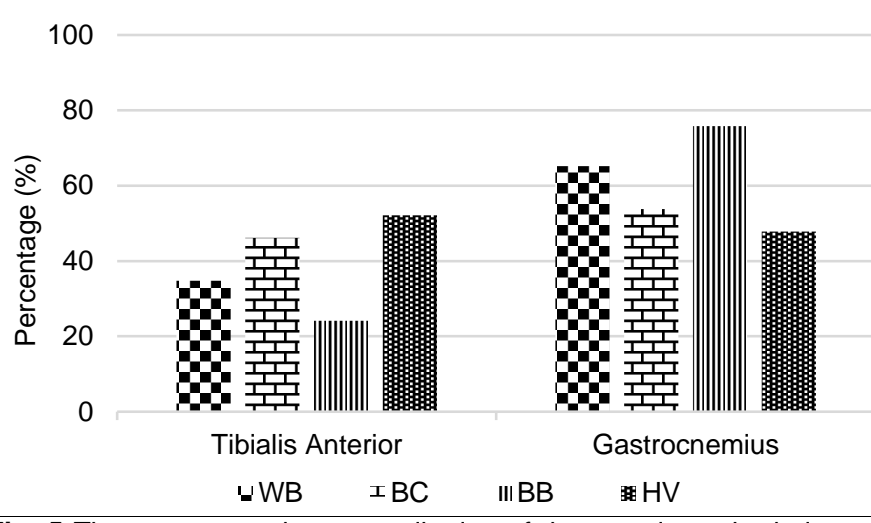

Fig. 5 The percentage input contribution of the muscle to the balance training devices.

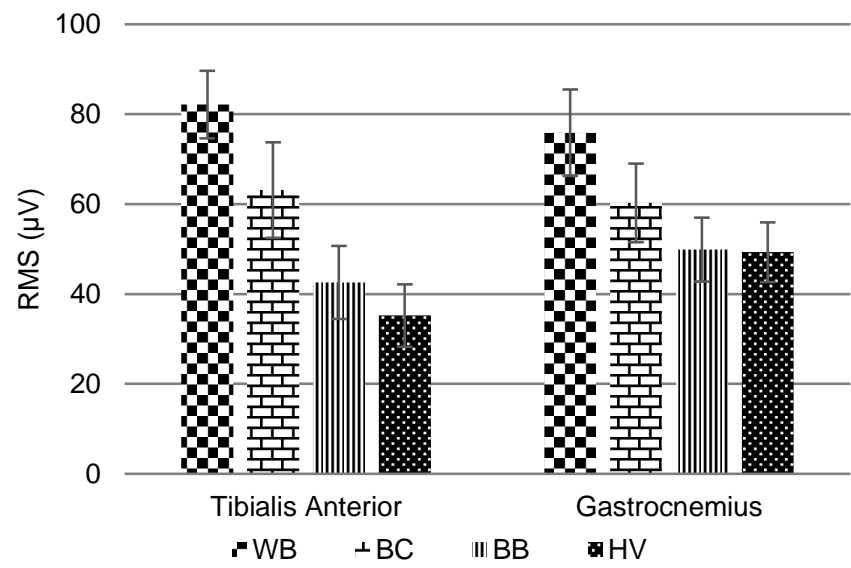

Fig. 6 The root-mean square (RMS) of the tibialis anterior and gastrocnemius muscle for balance training devices.

\section{Muscle fatigue measurement}

In the Fig. 5 below, the value of the median frequency shows that there is not much different between the devices. Based on the ANOVA analysis, there was no significant different between the balance training devices for both muscle as the p-value between the devices for the tibialis anterior is 0.8539 and gastrocnemius muscle is 0.9651 .

60

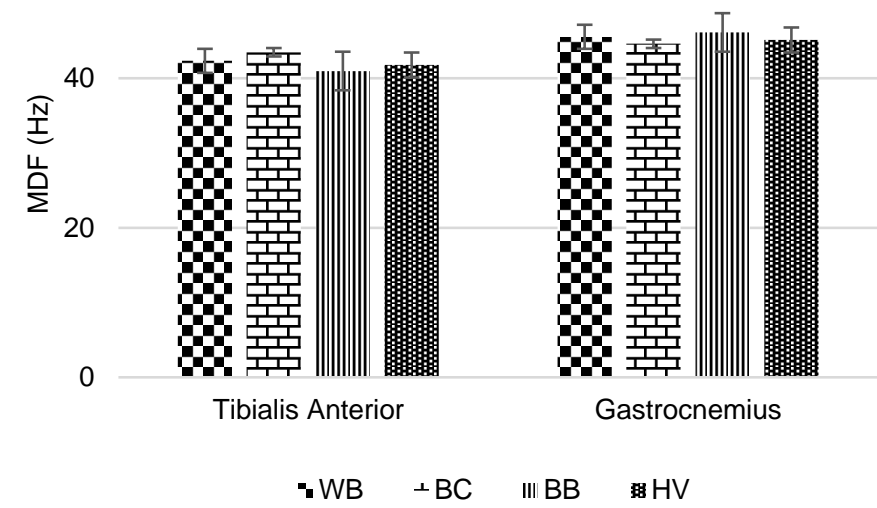

Fig. 5 The median frequency (MDF) value of the tibialis anterior and gastrocnemius muscle for balance training devices. 
Besides that, the highest firing rate of motor unit for tibialis anterior is balance cushion meanwhile for the gastrocnemius muscle is bosu ball. But generally, the firing rate for all the balance training is almost same. This result indicates that all devices produce a similar intensity of work and difficulties for both muscles.

However, it is clear that tibialis anterior muscle is more fatigue compared to gastrochemius muscle as the median frequency is less. Besides, Table 3 shows the summary of one way analysis of variance (ANOVA) among balance training devices for each muscle.

Table 3 Summary of One way analysis of variance (ANOVA) among balance training devices for each muscle.

\begin{tabular}{ccccc}
\hline Muscle & Parameter & $\begin{array}{c}\text { Degree } \\
\text { of } \\
\text { freedom }\end{array}$ & F-value & $\begin{array}{c}\text { P- } \\
\text { value }\end{array}$ \\
\hline Gastrocnemius & ARV & 3 & 0.7461 & 0.5288 \\
Tibialis Anterior & 3 & 0.0615 & 0.9798 \\
\hline Gastrocnemius & RMS & 3 & 2.2398 & 0.0932 \\
Tibialis Anterior & & 3 & 6.9268 & 0.0004 \\
\hline Gastrocnemius & Median & 3 & 0.0902 & 0.9651 \\
Tibialis Anterior & frequency & 3 & 0.2599 & 0.8539 \\
\hline
\end{tabular}

\section{DISCUSSION}

The muscle contribution of agonist (tibialis anterior) and antagonist muscle (gastrocnemius) have shown the dominant muscle generated for all balance training devices. Overall, gastrochemious is the dominant muscle for all balance training device. But, hover board shows a difference pattern where tibialis anterior was more dominant than gastronemious. This maybe caused by the nature of created by the device. Hover board allows upward-downward tilting motion for about 6 degrees and forward-backward motion at the same time while the other devices allow more static movement.

Based on the RMS results, the level of muscle activation was increased from hover board, bosu ball, balance cushion, and wobble board. According to the previous research, the less stable balance training devices required more muscle activity than the more stable devices (Wolburg et al., 2016). This finding also similar to previous study where force is directly proportional to the EMG signal (Fukuda et al., 2010). This shows that the muscle needs more strength to keep stable on the most unstable devices.

Futhermore, 120 seconds of recording time seems unable to create muscle fatigues as no changes was observed during the first $60 \mathrm{~s}$ and the last 60 seconds of recording time. This result suggested that a more longer time is necessary to create muscle fatigue. The result shows that the median frequency for all devices are almost the same. However, there are diffences between both muscles. Tibilais anterior muscle recorded less medial frequency value compared to gastrochemious muscle which indicates that tibialis anterior slightly less action potential firing rate than gastrocnemious. According to previous research, it was reported that the more the strength of muscle used, the more the firing rate(De Luca \& C Hostage, 2010). The result on input percentage have also indicated that gastrochemious were contributed more than tibialis anterior muscle to maintain balance position the devices.

According to previous study, wobble board, bosu ball and balance cushion were suitable for people with ankle injuries. In addition, wobble board was reported able to improve the upper limb injuries meanwhile balance cushion can be used for general strength training (Latip et al., 2015). Results from this study suggests that the unstability level of the balance training devices affected the muscle activity. Fig. 6 below shows the suggested rank of balance training device based on the RMS value. This preliminary rank might be a guide for recovery or rehabilitation purpose. However, further study is still warranted to identify effectiveness and reliability of the rank to the recovery process.

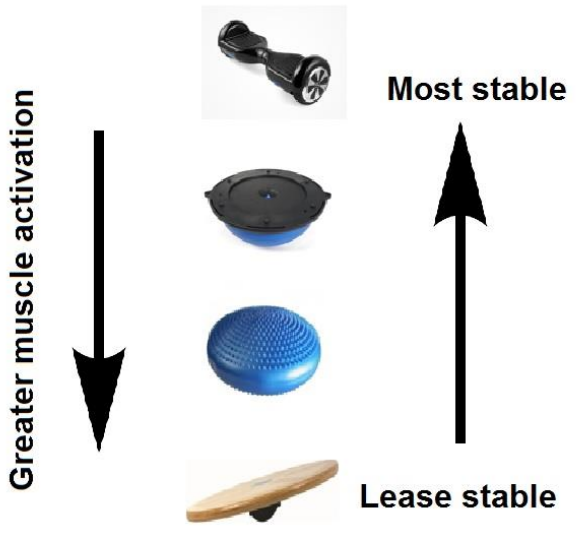

Fig. 6 The preliminary rank of balance training devices based on the root mean square (RMS) value.

Based on the three measurement such as RMS , ARV and median frequency, it was observed that there is no significant difference between hover board and the other establised balance training devices. These have shown that hover board offers a promising feature to be an alternative device for balance training. But before that, further investigation is needed especially issues related to user safety. According to previous study, it was recorded several accident related to hover board. Most cases were related to injuries including fractures and serious burns due to a malfunction of the device's battery (Bandzar, Bandzar, Gupta, \& Atallah, 2016). Besides, in 2016, American government has increased awareness programme related to the use of hover board including recommendation on the use of helmet and paddings, guidance on safe use of hoverboard such as avoiding vehicle, uses on flat surface and proper equipments (Robinson, Agarwal, Chaudhary, Costello, \& Simon, 2016).

There are some limitations of this study that need to be considered. One to the limitation includes measurement of stability level of balance training device. In this study,stability level of balance training device used was based on qualitative feedback from the subject. Quantitive measurement definitely will improve the quality of results. Besides that, duration of data recording should be increased. In this study, subjects were asked to stand on the devices for 120 seconds. However, the periods was not enough to create muscle fatigue condition.

\section{CONCLUSION}

As a conclusion, there is not much difference between the balance training device and hover board in term of physiological effects of both tibialis anterior and gastrochemious muscle. This study also suggested that hoverboard offers a promising feature to be an alternative device for balance training device.The results also highlighted the training intensity for each devices and classify them according to their effects on muscle activation. However, further investigation is still needed to identify which devices suited for rehabilitation of particular injury and sports training regimes so that a better rehabilitation intervention can be provided.

\section{ACKNOWLEDGEMENT}

This research was supported by Potential Academic Scheme Grant (PAS) (Research University Grant-02K37). The authors would like to thank Bio Signal Processing (BSP) research group member and Motion Lab Analysis member for assistance with the EMG recording device and research methodology. Besides, the authors would like to thank all participants who involved in this study. This work is an extension to 
International Medical Device and Technology Conference 2017 (iMEDiTEC 2017).

\section{REFERENCES}

Amtmann, J., Loch, K., Todd, C. S., \& Spath, W. (2013). Heart Rate Effects of Longboard Skateboarding. Intermountain Journal of Sciences, 19(1-4), 22-27.

Azaman, A., \& Yamamoto, S. i. (2014). Balance process during repeated surface perturbation: Adaptation response of joint stiffness and muscle activation. Paper presented at the 2014 IEEE Conference on Biomedical Engineering and Sciences (IECBES), Miri, Sarawak, Malaysia.

Bandzar, S., Bandzar, A., Gupta, S., \& Atallah, H. (2016). 158 epidemiology of hoverboard injuries requiring emergency care. Annals of Emergency Medicine, 68(4), S62-S63. doi: 10.1016/j.annemergmed.2016.08.171

Cifrek, M., Medved, V., Tonković, S., \& Ostojić, S. (2009). Surface EMG based muscle fatigue evaluation in biomechanics. Clinical Biomechanics, 24(4), 327-340. doi:10.1016/j.clinbiomech.2009.01.010

Cimadoro, G., Paizis, C., Alberti, G., \& Babault, N. (2013). Effects of different unstable supports on EMG activity and balance. Neuroscience Letters, 548(Supplement C), 228-232. doi: 10.1016/j.neulet.2013.05.025

De Luca, C., \& C Hostage, E. (2010). Relationship between firing rate and recruitment threshold of motoneurons in voluntary isometric contractions. Journal of Neurophysiology, 104(2), 1034-1046. doi: 10.1152/jn.01018.2009

Fogg, B. (December, 2002). Persuasive technology: Using computers to change what we think and do. Ubiquity, Article No. 5. doi: 10.1145/764008. 763957

Fukuda, T. Y., Rossetto, F. M., Magalhães, E., Bryk, F. F., Lucareli, P. R. G., \& Carvalho, N. A. D. A. (2010). Short-term effects of hip abductors and lateral rotators strengthening in females with patellofemoral pain syndrome: A randomized controlled clinical trial. Journal of Orthopaedic \& Sports Physical Therapy, 40(11), 736-742. doi: 10.2519/jospt.2010.3246

Goh, D. H.-L., \& Razikin, K. (2015). Is Gamification Effective in Motivating Exercise? In M. Kurosu (Ed.), Human-Computer Interaction: Interaction Technologies: 17th International Conference, HCI International 2015, Los Angeles, CA, USA, August 2-7, 2015, Proceedings, Part II (pp. 608-617). Cham: Springer International Publishing.

Hinman, M. R. (2002). Comparison of two short-term balance training programs for community-dwelling older adults. Journal of Geriatric Physical Therapy, 25(3), 10-15.

Kang, J. H., \& Hyong, I. H. (2012). Analysis of electromyographic activities of ankle muscles at different levels of instability of unstable surfaces. Journal of Physical Therapy Science, 24(12), 1333-1335.

Karashanov, A., Manolova, A., \& Neshov, N. (2016). Application for hand rehabilitation using leap motion sensor based on a gamification approach International Journal of Advance Research in Science and Engineering, 5(2), 61-69.

Kerr, J., Sallis, J. F., Saelens, B. E., Cain, K. L., Conway, T. L., Frank, L. D., \& King, A. C. (2012). Outdoor physical activity and self rated health in older adults living in two regions of the U.S. The International Journal of Behavioral Nutrition and Physical Activity, 9, 89. doi: 10.1186/1479-5868-989

Konrad, P. (2005). The ABC of EMG: A practical introduction to kinesiological electromyography. USA: Noraxon.
Latip, H. F. M., Omar, A. H., Shahrom, A., Azmi, F., \& Ridhwan. (2015). A Novel hybrid rehabilitation device for neuromuscular control exercise and rehabilitation training. Procedia Computer Science, 76(Supplement C), 368375. doi: 10.1016/j.procs.2015.12.311

Lee, J.-W., Yoon, S.-W., Kim, J.-H., Kim, Y.-P., \& Kim, Y.-N. (2012). The Effect of ankle range of motion on balance performance of elderly people. Journal of Physical Therapy Science, 24(10), 991-994. doi: 10.1589/jpts. 24.991

Nieratko, C. (2010, June 23). A perfect fit. Retrieved from http://www.espn.com/action/skateboarding/news/story?id=5301983

Oinas-Kukkonen, H., \& Harjumaa, M. (2008). A systematic framework for designing and evaluating persuasive systems. In H. Oinas-Kukkonen, P. Hasle, M. Harjumaa, K. Segerståhl, \& P. Øhrstrøm (Eds.), Persuasive Technology: Third International Conference, PERSUASIVE 2008, Oulu, Finland, June 4-6, 2008. Proceedings (pp. 164-176). Berlin, Heidelberg: Springer.

Pfusterschmied, J., Lindinger, S., Buchecker, M., Stöggl, T., Wagner, H., \& Müller, E. (2013). Effect of instability training equipment on lower limb kinematics and muscle activity. [Auswirkung instabiler Trainingsgeräte auf die Kinematik und Muskelaktivität unterer Extremitäten]. Sportverletz Sportschaden, 27(1), 28-33. doi: 10.1055/s-0032-1330725

Phinyomark, A., Thongpanja, S., Hu, H., Phukpattaranont, P., \& Limsakul, C. (2012). The usefulness of mean and median frequencies in electromyography analysis. In G. R. Naik (Ed.), Computational Intelligence in Electromyography Analysis - A Perspective on Current Applications and Future Challenges (pp. Ch. 08). Rijeka: InTech.

Robinson, T., Agarwal, M., Chaudhary, S., Costello, B. E., \& Simon, H. K. (2016). Pediatric hoverboard injuries: A need for enhanced safety measures and public awareness. Clinical Pediatrics, 55(11), 1078-1080. doi:10.1177/0009922816664066

Schwartz, F. P., Bottaro, M., Celes, R. S., Pereira, M. C., Rocha Júnior, V. d. A., \& Nascimento, F. A. d. O. (2014). Study of muscle fatigue in isokinetic exercise with estimated conduction velocity and traditional electromyographic indicators. Revista Brasileira de Engenharia Biomédica, 30, 312-321.

Stirn, I., Jarm, T., Kapus, V. P., \& Strojnik, V. (2013). Evaluation of mean power spectral frequency of EMG signal during 100 metre crawl. European Journal of Sport Science, 13(2), 164-173. doi: 10.1080/17461391.2011.630100

van der Woude, L. H. V., de Groot, S., Bijker, K. E., Dekker, R., Th van Aanholt, P. C., Hoekstra, F., . . Houdijk, H. (2010). 4th International State-of-the-artcongress 'Rehabilitation: Mobility, Exercise \& Sports'. Disability and Rehabilitation, 32(26), 2149-2154. doi: 10.3109/09638288.2010.525289

Wolburg, T., Rapp, W., Rieger, J., \& Horstmann, T. (2016). Muscle activity of leg muscles during unipedal stance on therapy devices with different stability properties. Physical Therapy in Sport, 17(Supplement C), 58-62. doi: 10.1016/j.ptsp.2015.05.001

Yoon, S.-W. (2017). Analysis of the muscular activities of the tibialis anterior and gastrocnemius muscles in functional reach. Journal of Physical Therapy Science, 29(5), 851-853. doi: 10.1589/jpts.29.851

Zuckerman, O., \& Gal-Oz, A. (2014). Deconstructing gamification: Evaluating the effectiveness of continuous measurement, virtual rewards, and social comparison for promoting physical activity. Personal and Ubiquitous Computing, 18(7), 1705-1719. doi: 10.1007/s00779-014-0783-2 